\title{
Nucleoside Diphosphate Kinase Homolog 5
}

National Cancer Institute

\section{Source}

National Cancer Institute. Nucleoside Diphosphate Kinase Homolog 5. NCI Thesaurus. Code C92504.

Nucleoside diphosphate kinase homolog 5 (212 aa, $24 \mathrm{kDa}$ ) is encoded by the human NME5 gene. This protein may play a role in both sperm differentiation and apoptosis regulation. 